\title{
MicroRNA-122 mimic transfection contributes to apoptosis in HepG2 cells
}

\author{
HONGYAN HUANG ${ }^{1,2}$, YUEYONG ZHU ${ }^{1}$ and SHAOYANG $\mathrm{LI}^{3}$ \\ ${ }^{1}$ Liver Diseases Research Center, The First Affiliated Hospital of Fujian Medical University, Fuzhou, Fujian 350005; \\ ${ }^{2}$ Department of Gastroenterology, Taizhou Municipal Hospital; ${ }^{3}$ Department of Neurosurgery, \\ The First People's Hospital of Taizhou, Taizhou, Zhejiang 318000, P.R. China
}

Received September 17, 2014; Accepted June 5, 2015

DOI: $10.3892 / \mathrm{mmr} .2015 .4254$

\begin{abstract}
There is currently a requirement for effective treatment strategies for human hepatocellular carcinoma (HCC), a leading cause of cancer-associated mortality. MicroRNA-122 (miR-122), a repressor of the endogenous apoptosis regulator $\mathrm{Bcl}-\mathrm{w}$, is frequently downregulated in HCC. Thus, it is hypothesized that the activation of miR-122 may induce selective hepatocellular apoptosis via caspase activation in a model of HCC. In the present study, an miR-122 mimic transfection was performed in HepG2 cells, and used to investigate the role and therapeutic potential of miR-122 in the regulation of HCC-derived cell lines. The apoptotic rates of HepG2 cells were significantly increased following miR-122 mimic transfection. Reverse transcription-polymerase chain reaction analysis revealed that Bcl-w mRNA was significantly reduced, while the mRNA levels of caspase- 9 and caspase-3 were markedly increased. The immunocytochemistry results supported the mRNA trends. Collectively, the present results suggest that endogenous miR-122 contributes to HepG2 apoptosis and that transfection of mimic miR-122 normalizes apoptotic levels in a model of HCC.
\end{abstract}

\section{Introduction}

Hepatocellular carcinoma (HCC), the most common primary malignancy of the liver, is the leading cause of cancer-associated mortality, the incidence of which has been increasing exponentially worldwide in recent decades (1-3). Surgical resection and liver transplantation are recognized as potentially curative therapeutic strategies, however, the five-year survival rate of $\mathrm{HCC}$ remains at $<7 \%$. For the majority of patients, $\mathrm{HCC}$ is diagnosed in the advanced tumor stages due to the asymptomatic nature of HCC. At this point, the scarcity

Correspondence to: Dr Yueyong Zhu, Liver Diseases Research Center, The First Affiliated Hospital of Fujian Medical University, 20 Cha Zhong Zhi Lu, Fuzhou, Fujian 350005, P.R. China E-mail: yueyongzhu@yahoo.com

Key words: microRNA-122, mimic, apoptosis, HepG2 cell of donated livers for transplantation severely limits the options for patients with HCC (4,5). For advanced and unresectable HCC, chemotherapy, transarterial chemoembolization, ablation (radiofrequency ablation, microwave, laser-induced interstitial thermotherapy, high-intensity focused ultrasound ablation, cryoablation and chemical ablation), and stereotactic body radiation therapy (proton beam therapy) at present are often the only measures for treating the disease. However, an ideal treatment strategy is yet to be elucidated, as outcomes associated with the existing treatments are generally poor due to low tolerance, low efficacy and a high recurrence rate (6). Therefore, a novel therapeutic modality is required.

MicroRNA (miR)-122, a liver-specific miR, comprises $70 \%$ of the total $\mathrm{miR}$ population of the liver. It is downregulated in human HCC and is associated with hepatocarcinogenesis. miR-122 inhibits hepatoma cell proliferation and promotes apoptosis of HCC cells (7). Gramantieri et al (8) found that decreased expression of miR-122a promoted the expression of cyclin G1 and enabled more cells to enter into S phase, thereby contributing to the proliferation of malignant liver cancer cells. Another study found that the Bcl-2 anti-apoptotic family member Bcl-w, also termed BCL2L2 was a direct target of miR-122. Bcl-w expression may be downregulated by miR-122 and subsequently inhibit cancer cell proliferation via caspase-3 apoptotic activation in HCC cells (9).

The above-mentioned findings indicate that hepatocarcinogenesis may be inhibited via exogenous miR-122 mimic transfection into a pathogenic carcinoma or HCC. The interception of a pathogenic cell survival pathway via mimic miR-122 transfection may be an important step toward a novel therapeutic treatment for patients with HCC. In the present study, a liposome-mediated synthetic miR-122 analog (an miR-122 mimic) was transfected into HepG2 cells. Subsequently, the apoptotic rates of HepG2-transfected cells were analyzed, and the protein and mRNA levels of Bcl-w, caspase- 9 and caspase-3 were investigated to examine the possible pathway by which miR-122 is contributing to apoptosis in HepG2 cells.

\section{Materials and methods}

Cell culture. HepG2 cells were obtained from Professor Weng Shengmei of the College of Pharmacy, Fujian Medical University (Fuzhou, China) and maintained in RPMI-1640 medium (Gibco 
Table I. Polymerase chain reaction primer sequences.

\begin{tabular}{lccc}
\hline Gene & Fragment, bp & Upstream & Downstream \\
\hline$\beta$-actin & 556 & 5'-AAA GAC CTG TAC GCC AAC ACA G-3' & 5'-TTT TAG GAT GGC AAG GGA CTT C-3' \\
Bcl-w & 237 & 5'-GCA GCT GGA GATGAG TTC G-3' & 5'-CCA TCC ACT CCT GCA CTT G-3' \\
Bax & 223 & 5'-GTT TCA TCC AGG ATC GAG C-3' & 5'-GCC GTC AGA AAA CAT GTC AG-3' \\
Caspase-9 & 240 & 5'-CAG ACC AGA GAT TCG CAA AC-3' & 5'-CGC AAC TTC TCA CAG TCG AT-3' \\
Caspase-3 & 200 & 5'-ATG AGA GGC AAT GAT TGT TAA T-3' & 5'-CCC ACA GAT GCC TAA GTT CT-3' \\
\hline
\end{tabular}

Bax, Bcl-2-associated X protein.

Life Technologies, Grand Island NY, USA) supplemented with $10 \%$ fetal calf serum (Gibco Life Technologies) at $37^{\circ} \mathrm{C}$ with $5 \% \mathrm{CO}_{2}$ (no antibiotics). HepG2 cells in the logarithmic growth phase were acquired and the cellular concentration was adjusted to $1 \times 10^{6}$ cells $/ \mathrm{ml}$. The cells were then incubated at a density of $2 \mathrm{ml} /$ well in 6-well plates for $24 \mathrm{~h}$. HepG2 cells were randomly divided into four groups, normal cultured HepG2 cells, the transfection reagent control group, the negative control group [transfected with non-specific sequence control short interfering (si)RNA] and miR-122 mimic transfection group. Biological duplicates were included for each group and all experimental procedures were repeated three times.

miR-122 transfection. A commercial miR-122 mimic was used for transfection with the following sequence: 5'-UGGAGUGUGACAAUGGUGUUUG-3' (synthesized by Qiagen; Germantown, MD, USA). The AllStars Negative Control siRNA (Qiagen; cat. no. 1027280) served as a negative control and an AllStars Hs Cell Death Control siRNA (cat. no. 1027298) served as a positive control. Transfection was achieved using the HiPerFect transfection reagent (Qiagen) according to the manufacturer's instructions. Briefly, $5 \mu \mathrm{l}$ transfection reagent was mixed with $2.5 \mu \mathrm{l} 2-\mu \mathrm{M}$ control siRNA, AllStars Hs Cell Death Control siRNA, or miR-122 mimic and $100 \mathrm{ml}$ serum-free media, then incubated for $10 \mathrm{~min}$.

Serum-supplemented media was removed from the cell cultures and cells were washed with serum-free RPMI-1640. Fresh, serum-free media $(900 \mu \mathrm{l})$ was then added to the monolayer of cells. Subsequently, $100 \mu \mathrm{l}$ siRNA/mimic-HiPerFect mixture was added into each well and mixed gently. The cells were further incubated for 24,48 and $72 \mathrm{~h}$ prior to harvesting.

Transfection efficiency. AllStars Hs Cell Death Control siRNA transfection induces cellular apoptosis. The targets of the siRNA are predominantly genes, which are associated with cell apoptosis and caspase- 3 or -8 activation. The cells that were successfully transfected with AllStars Hs Cell Death Control siRNA were expected to undergo apoptosis within 24-72 h. AllStars Hs Cell Death Control-transfected HepG2 cells and the non-transfected control cells were cultivated for 24, 48 and $72 \mathrm{~h}$. At each of these time points, cultures were analyzed for apoptosis under a (DM 2500B Leica optical microscope, at a magnification of x500 (Leica Microsystems GmbH, Wetzlar, Germany). The transfection ratio (TR) was calculated according to the formula: TR $(\%)=$ (apoptotic cell number in the AllStars
Hs Cell Death Control siRNA transfection group / total cells in this group - the apoptotic cell number in the non-transfected control group / total cells in the non-transfected group) x 100 .

Flow cytometric analysis of apoptotic rate. Cell samples from all four experimental groups were stained using an Annexin V apoptosis detection kit (MP Biomedicals, Shanghai, China). The apoptotic rate of the cells was detected by flow cytometry (BD FACSVerse flow cytometer; BD Biosciences, San Jose, CA, USA). The cells were collected at a $1 \times 10^{6}$ cells $/ \mathrm{ml}$ density per sample after culturing for 24,48 and $72 \mathrm{~h}$. The cells were then centrifuged at 27.75-111 x g for $5 \mathrm{~min}$, and the supernatant was removed and washed with phosphate-buffered saline (PBS). A total of $100 \mu 1 \mathrm{lX}$ Annexin-binding buffer was added to resuspend the cells. Subsequently, $5 \mu \mathrm{l}$ Alexa fluor 488 (green) Annexin $\mathrm{V}$ and $1 \mu \mathrm{l} 100-\mu \mathrm{g} / \mathrm{ml}$ propidium iodide (PI; red) was added to the cells. The cells were incubated at room temperature in the dark for $15 \mathrm{~min}$. Following incubation, $400 \mu \mathrm{l} 1 \mathrm{X}$ Annexin-binding buffer was added to the cells and the mixture was gently mixed. The cellular concentration was adjusted to $1 \times 10^{6}$ cells $/ \mathrm{ml}$. The time periods that exhibited the highest TRs from the previous screen were selected and assessed via flow cytometry. In the bivariate flow cytometry scatter plots, the lower left quadrant exhibits living cells [fluorescein isothiocyanate (FITC)-/PI-]; the upper right quadrant indicates non-living cells/necrotic cells (FITC+/PI+); the lower right quadrant demonstrates apoptotic cells (FITC+/PI-); and the upper left quadrant suggested early apoptotic cells (FITC+/Pl-)..

Reverse transcription-polymerase chain reaction (RT-PCR). Total mRNA was extracted from cells using TRIzol reagent and reverse transcribed into cDNA using an RT-PCR kit (Invitrogen Life Technologies, Grand Island, NY, USA). The mRNA levels of Bcl-w, Bcl-2-associated X protein (Bax), caspase- 9 and caspase- 3 were then detected with RT-PCR using gene-specific probes (Table I; Shanghai Dinghan Biotechnology Co. Ltd., Shanghai, China) and $\beta$-actin served as an internal control. The PCR cycle parameters were as follows: Denaturation at $4^{\circ} \mathrm{C}$ for $5 \mathrm{~min}$, amplification at $9^{\circ} \mathrm{C}$ for $30 \mathrm{sec}, 57^{\circ} \mathrm{C}$ for $30 \mathrm{sec}$ and $72^{\circ} \mathrm{C}$ for $45 \mathrm{sec}$ sequentially for 30 cycles in total, and extension at $7^{\circ} \mathrm{C}$ for $7 \mathrm{~min}$. The PCR products were separated by $1.2-1.3 \%$ agarose gel electrophoresis. A total of $5 \mu \mathrm{l}$ of each product was added into five combs, and run twice at $110 \mathrm{mV}$ for $40 \mathrm{~min}$, prior to being visualized with grayscale scanning (Gel DocTM EZ 
A

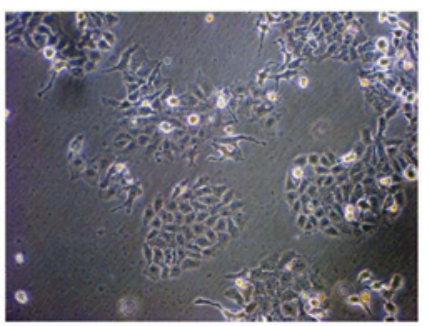

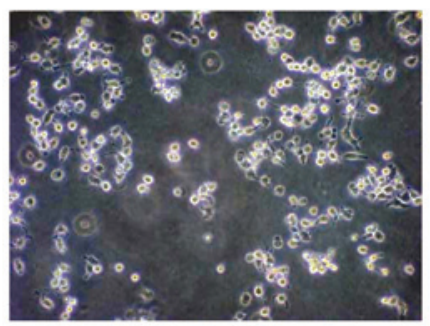

Figure 1. HepG2 cells are reactive to transfection with AllStars Hs Cell Death Control siRNA. (A) HepG2 cells were visualized under an ordinary optical microscope $24 \mathrm{~h}$ after transfection. (B) At $72 \mathrm{~h}$ after liposome-mediated transfection with AllStars Hs Cell Death Control siRNA, HepG2 cells appeared to decrease in viability. siRNA, short interfering RNA. Magnification, x400.

A

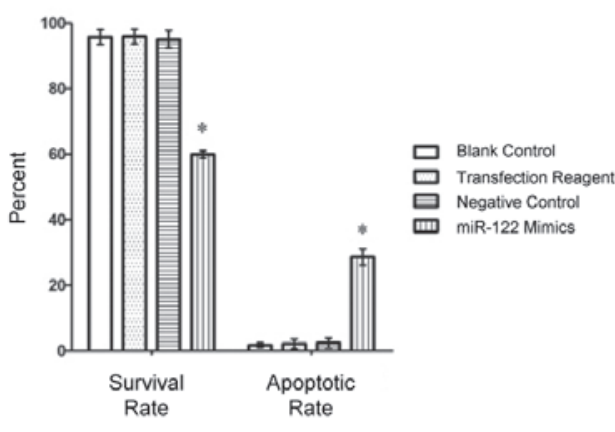

B

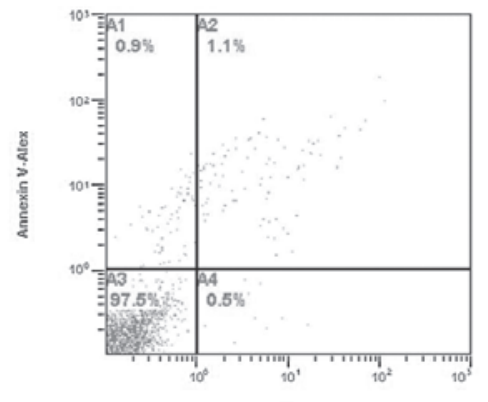

D

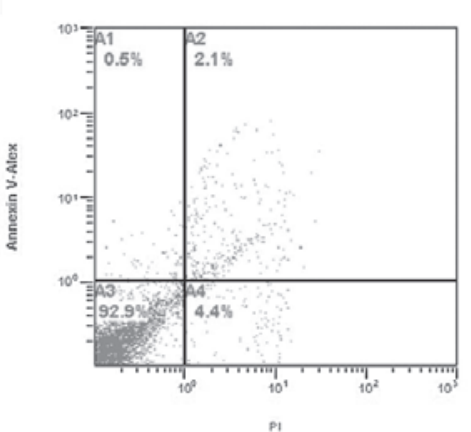

C

[F1)Ungoted] 20016978. ImA : FL3 LOQNFL LOG

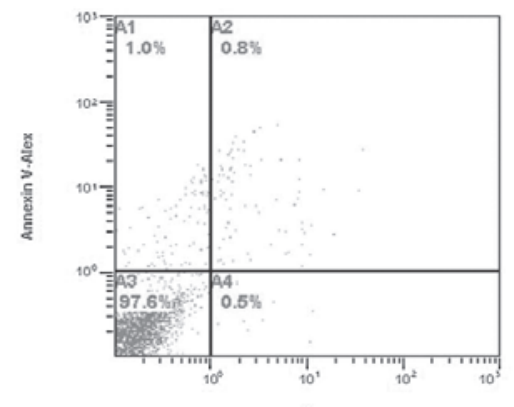

E

(F1) (Ungsed) 20017012.1md : FL3 LOOFL1 LOC

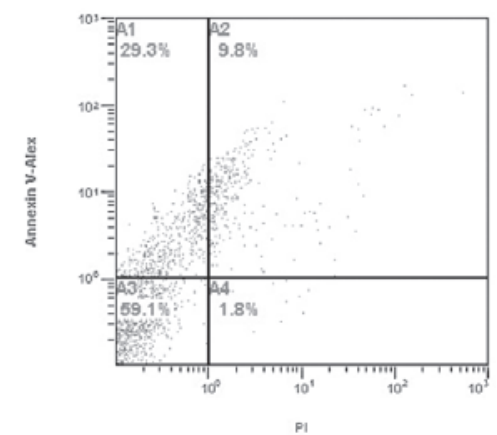

Figure 2. Survival rates decrease and apoptotic rates increase in miR-122 mimic-transfected cells. Annexin V staining was utilized to assess survival and apoptotic rates of HepG2 cells. (A) Survival rate of the miR-122 mimic-transfected cells fell below the rates of all experimental controls. The apoptotic rates of the miR-122 mimic-transfected group were significantly higher than control levels $\left({ }^{*} \mathrm{P}<0.01\right)$. No statistical significance was detected between the control groups, which included non-transfected 'blank' control cells, a transfection reagent positive control group and a non-sequence specific transfected negative control group. Flow cytometry was used as a secondary assay of apoptosis. (B-E) A1 quadrant, early apoptosis cells (FITC+/Pl-); A3 quadrant, living cells (FITC-/PI-); A2 quadrant, non-living cells, which may also express necrotic cells (FITC+/PI+); A4 quadrant, apoptotic cells (FITC+/PI-). All data are expressed as the mean \pm standard deviation. miR, microRNA; FITC, fluorescein isothiocyanate; PI, propidium iodide.

Imager system; Bio-Rad Laboratories, Inc., Hercules, CA, USA).

Immunocytochemsitry. Bcl-w, Bax, caspase-9 and caspase- 3 were selected as target proteins. Glass coverslips $(1.8 \times 20 \times 20 \mathrm{~mm})$ were soaked in dilute hydrochloric acid overnight and washed with double distilled water prior to drying and autoclaving. The coverslips were placed into 6-well plates (1 coverslip/well) and HepG2 cells were inoculated in these wells at a density of $1 \times 10^{5}$ cells $/ \mathrm{ml}$. After $24 \mathrm{~h}$ cultivation, the cell densities were of $40-50 \%$. The coverslips recovered by cells were divided into four experimental groups for each target protein, two coverslips per group. Each group was transfected with miR-122 mimic, negative control siRNA, transfection reagent and blank control, respectively, then cultivation was continued for $24 \mathrm{~h}$. In addition, two coverslips were randomly selected from each experimental group for immunocytochemical negative controls to verify true positive rather than false positive. For each target protein (Bcl-w, Bax, caspase 9 and caspase 3), both immunohistochemical negative and immunohistochemical positive controls were used for contrast analysis in each experimental groups in order to verify true positive rather than false positive immunohistochemistry. These coverslips were 

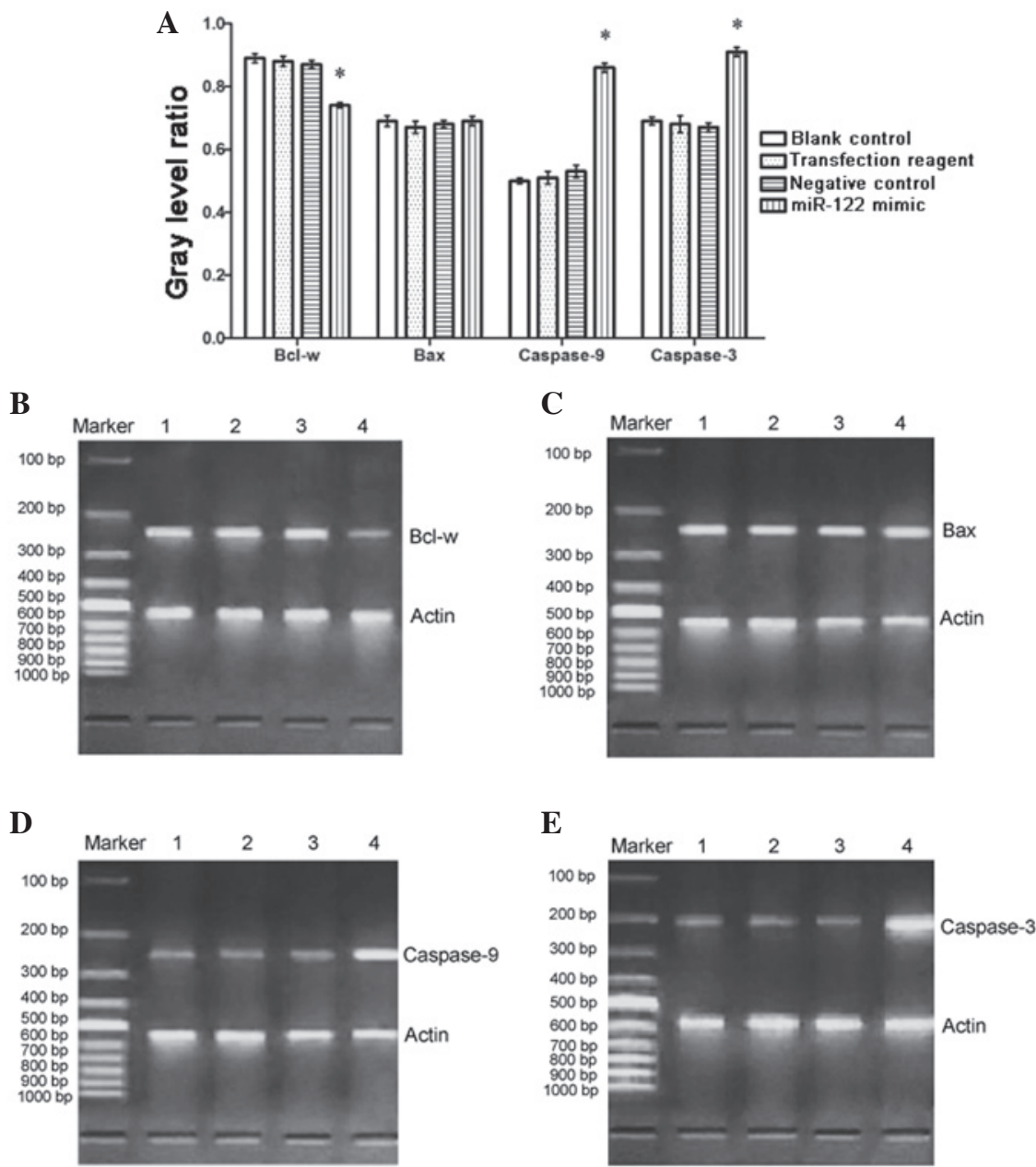

Figure 3. mRNA levels of cell survival-associated genes are altered by miR-122 mimic transfection. Reverse transcription PCR was used with gene-specific probes, and the PCR product was analyzed with gel electrophoresis and grayscale scanning. (A) Gray level ratios depicting PCR products normalized to internal control ( $\beta$-actin) indicate that Bcl-w mRNA is significantly decreased upon miR-122 mimic transfection ("P<0.01). Bax mRNA appears unchanged by the transfection, while caspase-3 and -9 undergo a significant increase following miR-122 mimic transfection ("P<0.01). (B-E) Gel electrophoresis results yielded the appropriate PCR product sizes expected for each PCR probe. Lane 4 brightness appeared (B) dimmer for the Bcl-w band, (C) unchanged for the Bax band, and brighter for the (D) caspase-9 and (E) caspase-3 bands. The actin product band was unchanged in all runs. Lane 1 represents non-transfected HepG2 cells, lane 2 indicates the AllStars Hs Cell Death control transfection group, lane 3 indicates the non-sequence specific negative control transfection group and lane 4 depicts the miR-122 mimic-transfected experimental group. All data are expressed as the mean \pm standard deviation. PCR, polymerase chain reaction; miR, microRNA; Bax, Bcl-2-associated X protein.

retrieved from the wells and fixed with ice-cold acetone. The cells were next prepared for immunocytochemistry using a commercial streptavidin-peroxidase kit according to the manufacturer's instructions (Fuzhou Maixin Biotech Co., Ltd., Fuzhou, China). Compatible primary antibodies (Santa Cruz Biotechnology, Inc., Santa Cruz, CA, USA) included monoclonal mouse anti-human $\operatorname{Bax}(1: 200$; cat. no. sc-20067), caspase-9 (1:200; cat. no. sc-56073), and caspase-3 (1:200; cat. no. sc-65497), and polyclonal rabbit anti-human Bcl-w (1:200; cat. no. sc-130701), were incubated at $37^{\circ} \mathrm{C}$ for $1 \mathrm{~h}$. The primary antibody of the immunocytochemical negative control group was replaced with an equal amount of PBS buffer The secondary antibody used was horseradish peroxidase-labeled goat anti-mouse IgG (1:400; cat. no. sc-2004; Santa Cruz Biotechnology, Inc.), incubated at $37^{\circ} \mathrm{C}$ for $2 \mathrm{~h}$. Optical detection was achieved using the 3,3'-diaminobenzidine without chromogen (Beijing Zhongshan Golden Bridge Biotechnology Co., Ltd., Beijing, China). A total of two coverslips were collected from each of the experimental groups. The experiment was repeated three times for all groups. Finally, images (magnification, x400) were captured using a Leica Microscope (DM 2500B) and analyzed with Image-ProPlus software version 6.0 (Media Cybernetics, Inc., Rockville, MD, USA).

Statistical analysis. Data are expressed as the mean \pm standard deviation for each group. One-way analysis of variance was used to analyze the difference between groups and the least significant difference test was used for comparisons between two groups. Statistical analysis was performed using SPSS 18.0 (SPSS, Inc., Chicago, IL, USA). P $<0.01$ and $\mathrm{P}<0.05$ were considered to indicate a statistically significant difference.

\section{Results}

Required experimental transfection efficiency was met. AllStars Hs Cell Death Control siRNA was used to measure 

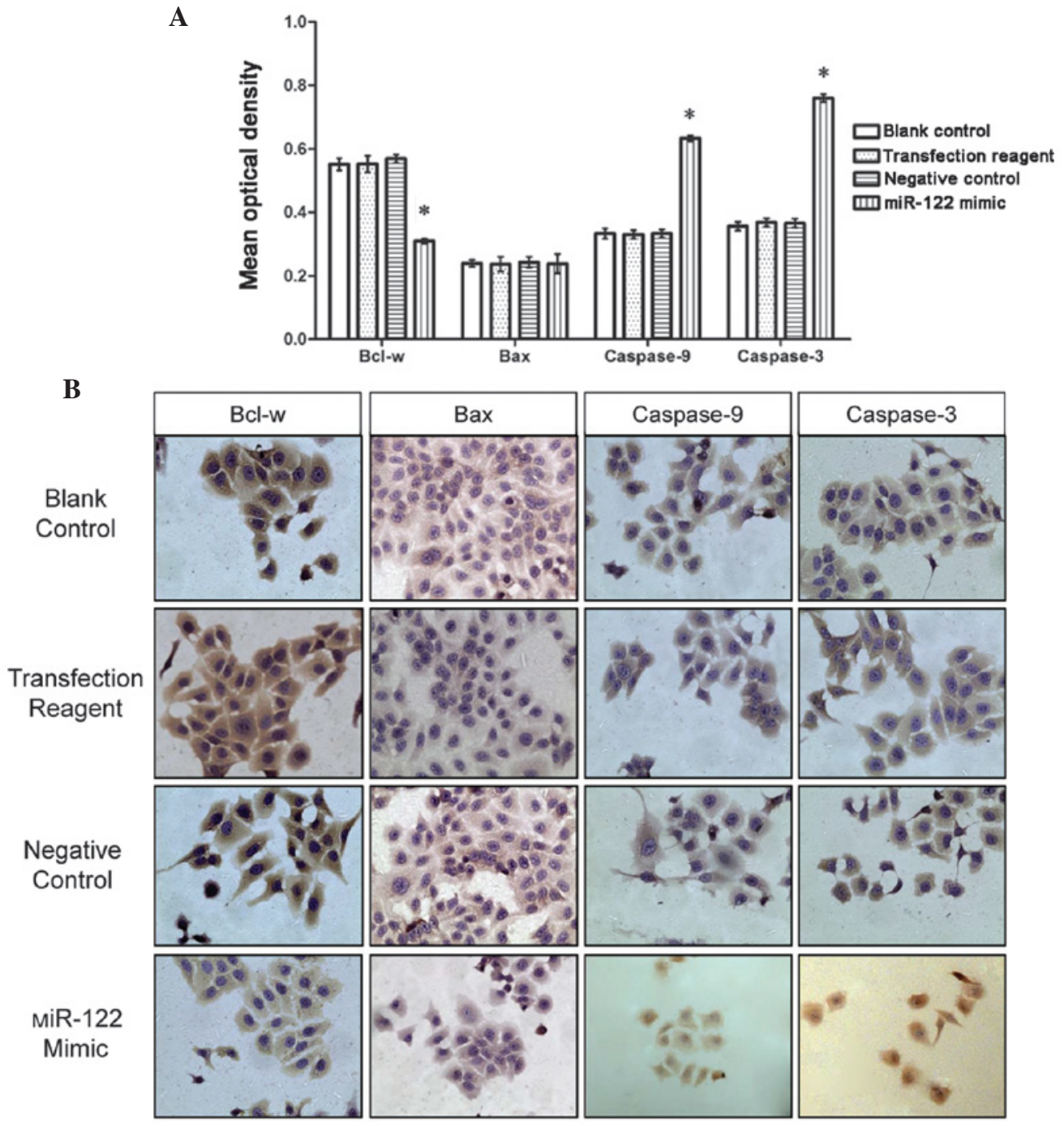

Figure 4. Immunocytochemical analysis of cell survival proteins in HepG2 transfected cells. Following immunostaining, images were captured using common light microscopy (magnification, $\mathrm{x} 400$ ) and the optical density of each image was measured using Image-ProPlus software. $\beta$-actin served as an internal reference to obtain normalized values. (A) The expression level of Bcl-w protein decreased in miR-122 mimic-transfected cells, while caspase-9 and caspase-3 protein expression levels increased ( $\mathrm{P}<0.01)$. Bax protein expression remained unchanged. (B) The protein detected is indicated in each individual image. The first row depicts representative images from the non-transfected 'blank' control group. The second row represents the AllStars Hs Cell Death Control siRNA-transfected cells, while the third and fourth rows indicate the negative control and miR-122 mimic-transfected cells, respectively. Bcl-w immunoreactivity appears weaker in the miR-122 mimic-transfected group, while Bax immunoreactivity appears unchanged. Caspase-3 and -9 appear marginally more intense in the mimic-transfected group versus the three controls. Data are expressed as the mean \pm standard deviation. siRNA, short interfering RNA; miR-122, microRNA-122; Bax, Bcl-2-associated X protein.

the transfection efficiency. The majority of HepG2 cells underwent visible apoptosis $72 \mathrm{~h}$ after HiPerFect-mediated transfection. The transfection efficiency was calculated at $80 \%$ (Fig. 1), which met the experimental requirements.

miR-122 mimic transfection increases apoptotic rate of HepG2 cells. To investigate the role of miR-122 in HCC cell death pathway regulation, HepG2 cells were transfected with an miR-122 mimic. The apoptotic rate of cells transfected with the mimic was $28.68 \pm 2.48 \%$. By contrast, the negative control, positive control, and non-transfection control groups exhibited apoptotic rates of $2.48 \pm 1.58 \%, 2.20 \pm 1.53 \%$ and $1.77 \pm 0.731 \%$, respectively. The apoptotic rate was significantly higher in the miR-122 mimic group than in any of the control groups (Fig. 2; $\mathrm{P}<0.01$ ), while the differences among the control groups were not statistically significant. Additionally, the apoptotic rate of HepG2 cells in the miR-122 mimic group was higher at $24 \mathrm{~h}$ post-transfection than at $48 \mathrm{~h}$ and $72 \mathrm{~h}(\mathrm{P}<0.05$; data not shown).

Bcl-w is downregulated, whereas caspase-9 and caspase-3 are upregulated following miR-122 mimic transfection. HepG2 cells may express Bcl-w, Bax, caspase- 9 and caspase-3 mRNA under common medium culture conditions $\left(37^{\circ} \mathrm{C}\right.$, $5 \% \mathrm{CO}_{2}, 95 \% \mathrm{O}_{2}, 100 \%$ humidity). To assess whether miR-122 mimic transfection affects the basal levels of transcription in these genes, mRNA was measured via RT-PCR. It was identified that the expression of Bcl-w mRNA was downregulated in the miR-122 mimic group than in the negative, positive and non-transfected control groups (Fig. 3; P <0.01). Conversely, caspase- 9 and caspase- 3 mRNA were upregulated in the miR-122 mimic group compared with the controls (Fig. 3; 
$\mathrm{P}<0.01)$. The level of Bax mRNA did not significantly differ among the four groups.

To corroborate the mRNA trends, immunocytochemistry was performed on samples from each of the experimental groups. The immunopositive reaction of Bcl-w and Bax was localized to the cytoplasm, while caspase- 9 and caspase- 3 immunoreactivities were traced to the nucleus and (or) the cytoplasm. The positive staining of the cells was detected as either reddish-brown or dark claybank chromogenic coloration. Image-ProPlus software allowed analysis of the images and revealed that the distribution of Bcl-w, Bax, caspase-9 and caspase-3 occurred at different degrees of intensity in each group. The regions of the highest cellular density were selected and the average optical density of these regions was calculated under $5 \mathrm{X}$ high-power field magnification.

The Image-ProPlus analysis revealed that Bcl-w immunoreactivity was less intense in the miR-122 mimic transfection group compared with the negative, positive, and the non-transfected control groups; however, the opposite was observed for caspase-9 and caspase-3 reactivity (Fig. 4 ; $\mathrm{P}<0.01$ ). No differences were observed in the level of Bax immunoreactivity among the four groups (Fig. 4).

\section{Discussion}

To confirm whether miR-122 is responsible for regulating human HCC cell apoptosis and to examine a possible therapeutic intervention for HCC, HepG2 cells transfected with an miR-122 mimic were produced via cationic liposomes and the apoptotic rates of the cells were observed. Bcl-w, an anti-apoptotic gene of the Bcl-2 family (significant in the endogenous apoptotic pathway) and caspase- 3 and -9 were also analyzed for their role in miR-122-mediated HCC cell survival.

While numerous miRs are expressed in the liver, only miR-122 is expressed specifically and abundantly. Landgraf etal (10) found that liver-specific miR-122 is expressed from the early implantation stages and reaches half of its peak levels on approximately the 17th embryonic day. Before birth, miR-122 begins to approach peak levels $(50,000$ copies of miR-122 per liver cell) although a marginal and steady rise continues even after birth, indicating that miR-122 may be involved in the regulation of the differentiation and development of the liver (10). miR-122 expression decreases in all cells in HCC indicating that it may be closely-associated with hepatic function and certain diseases. Chang et al (11) found that miR-122 antisense oligonucleotides damage the liver and inhibit the synthesis of cholesterol, further supporting the importance of endogenous miR-122 for normal hepatic function.

miR-122 may inhibit the proliferation of HCC cells and induce apoptosis via two of its targets in HCC cells, cyclin G1 and $\mathrm{Bcl}-\mathrm{w}(9,12)$. Bcl-w is widely expressed in certain transformed tumor cell lines of epithelial origin, such as colon, cervical and breast cancer (13). It has been suggested that Bcl-w may suppress gastric cancer cell death by blocking stressactivated protein kinase/c-Jun N-terminal kinase activation, and inducing the migratory and invasive potential of cancer cells via increased matrix metalloproteinase-2 expression $(14,15)$. Bcl-w expression is also modulated by the Met/hepatocyte growth factor (c-Met) receptor and inhibits apoptosis in colorectal tumors. Additionally, a binding site of miR-122 may exist in the 3'-untranslated region (UTR) of Bcl-w (16,17).

Previous studies have identified two promoters of the miR-122 transcript in chromosome 18 of hepatocytes, however HepG2 cells are largely miR-122-deficient. Ma et al (18) expressed functional miR-122 via adenoviral vectors targeted to tumor cells originating from the liver (HepG2, Hep3B, Huh7 and PLC/PRF/5), lung (NCI-H460) and uterine cervix (HeLa) at high levels, and induce apoptosis and/or cell cycle arrest by decreasing the expression of Bcl-W and cyclin G1. Wu et al (19) transfected Huh-7 and HepG2 cells with miR-122 and an miR-122 antisense strand, respectively, and no significant difference was identified between the viabilities of the transfected HepG2 cells and the mock-transfected HepG2 cells. However, the viability of Huh-7 cells transfected with anti-miR-122 was significantly elevated $48 \mathrm{~h}$ after transfection. While this implies that the aberrant expression of miR-122 may contribute to hepatocarcinogenesis, whether the transfection of HCC cells with miR-122 mimics alleviates HCC remains controversial (19). In the present study, the apoptotic rate was significantly increased in miR-122 mimic-transfected cells, demonstrating that miR-122 mimic transfection induces apoptosis in HCC cells.

Bcl-w, an anti-apoptotic Bcl-2 family member, has been closely associated with cancer formation and progression, and identified as a target of miR-122. Its expression is downregulated by the binding of miR-122 to the 3 '-UTR of its transcript $(9,20)$. It has been reported that activators of the liver-specific microRNA in liver cancer cells are able to selectively induce apoptosis through caspase activation (21). Generally, there are three pathways of apoptosis: The death receptor pathway, the endoplasmic reticulum pathway and the mitochondrial pathway. During apoptosis, various pre-apoptotic molecules, including reactive oxygen species (ROS) and cytochrome $c$, are released by the mitochondria into the cytosol via the mitochondrial (mt) permeability transition pore (PTP). The opening and closing of the mtPTP is regulated by proteins of the Bcl-2 family (22). Among them, Bax is responsible for opening of the PTP, while Bcl-w is hypothesized to inhibit the channel from opening. Bax is a gene homologous to Bcl-w, however, they possess different 3'-UTRs. Bax is dynamic and able to form heterodimers with Bcl-w to inhibit apoptosis, however, it can also homodimerize and induce apoptosis. When Bax is overexpressed, it is easier for Bax to form homodimers, which could antagonize the protective tendency of Bcl-w to induce cell apoptosis. Therefore, the ratio of $\mathrm{Bax} / \mathrm{Bcl}-\mathrm{w}$ is theorized to be the lynchpin of apoptotic regulation. Activators of miR-122 may downregulate the expression of $\mathrm{Bcl}-\mathrm{w}$, thereby increasing the ratio of $\mathrm{Bax} / \mathrm{Bcl}-\mathrm{w}$ and increasing the opening capacity of the mtPTP channel, consequently generating more ROS and less antioxidant enzymes. ROS, important apoptosis-associated molecules, are able to further increase the rate of mtPTP opening and stimulate cytochrome $c$ outflow leading to apoptosis through cytochrome $c$-dependent caspase activation. The release of cytochrome $c$ activates a cascade of caspases through complex formation with apoptotic protease activating factor 1 . The complex activates procaspase- 9 and subsequently caspase-3, a critical and irreversible point in the progression of apoptosis.

In the present study, it is reported that Bcl-w mRNA decreased as the levels of caspase- 9 and caspase- 3 mRNA increased markedly. Furthermore, the apoptotic rate of 
miR-122 mimic-transfected cells is increased. miR-122 may be downregulating Bcl-w expression and contributing to the activation of caspase-9/caspase-3. It is likely that miR-122 is inhibiting the translation of the anti-apoptotic gene, Bcl-w and inadvertently activating the caspase-9/caspase- 3 mitochondrial pathway of apoptosis. The observation of these results in HepG2 cells suggests that endogenous miR-122 in HCC may be acting to inhibit the proliferation of HCC cells and promoting apoptosis. Further investigation into the ability of miR-122 mimics to counter HepG2 growth and viability are warranted considering the results presented in the current study. Stabilizing the plasmid or viral vector target RNA fragments may optimize the gene silencing effect and thus improve the effectiveness of the gene interference. Additionally, Bai et al (23) validated A distintegrin and metalloprotease family 10 , serum response factor and insulin-like growth factor 1 receptor as tumorigenic targets of miR-122, which require further investigation (23). Finally, the growth rate of HCC cells expressing miR-122 significantly decreased following exposure to a multikinase inhibitor. This suggests that there are various signaling pathways for the miR-122 mimic-associated downregulation of $\mathrm{HCC}$, in addition to the Bcl-w/caspase-3 pathway described in the present study. While all these points require further investigation, the case for miR-122 manipulation in the regulation of liver cancer cell growth is apparent and promising as a novel therapeutic approach for HCC.

\section{Acknowledgements}

The authors would like to acknowledge Dr. Marisol Resendiz of Clarity Manuscript Consultants LLC for her assistance in editing the manuscript.

\section{References}

1. McGlynn KA and London WT: Epidemiology and natural history of hepatocellular carcinoma. Best Pract Res Clin Gastroenterol 19: 3-23, 2005.

2. Parkin DM, Bray F, Ferlay J and Pisani P: Global cancer statistics, 2002. CA Cancer J Clin 55: 74-108, 2005.

3. Altekruse SF, McGlynn KA and Reichman ME: Hepatocellular carcinoma incidence, mortality, and survival trends in the United States from 1975 to 2005. J Clin Oncol 27: 1485-1491, 2009.

4. Azam F and Koulaouzidis A: Hepatitis B virus and hepatocarcinogenesis. Ann Hepatol 7: 125-129, 2008.

5. Kaihara S, Kiuchi T, Ueda M, Oike F, Fujimoto Y, Ogawa K, Kozaki K and Tanaka K: Living-donor liver transplantation for hepatocellular carcinoma. Transplantation 75 (3 Suppl): S37-S40, 2003.

6. Lopez PM, Villanueva A and Llovet JM: Systematic review: Evidence-based management of hepatocellular carcinoma-an updated analysis of randomized controlled trials. Aliment Pharmacol Ther 23: 1535-1547, 2006.

7. Nakao K, Miyaaki H and Ichikawa T: Antitumor function of microRNA-122 against hepatocellular carcinoma. J Gastroenterol 49: 589-593, 2014.
8. Gramantieri L, Ferracin M, Fornari F, Veronese A, Sabbioni S, Liu CG, Calin GA, Giovannini C, Ferrazzi E, Grazi GL, et al: Cyclin G1 is a target of miR-122a, a microRNA frequently down-regulated in human hepatocellular carcinoma. Cancer Res 67: 6092-6099, 2007.

9. Lin CJ, Gong HY, Tseng HC, Wang WL and Wu JL: miR-122 targets an anti-apoptotic gene, Bcl-w, in human hepatocellular carcinoma cell lines. Biochem Biophys Res Commun 375: 315-320, 2008.

10. Landgraf P, Rusu M, Sheridan R, Sewer A, Iovino N, Aravin A, Pfeffer S, Rice A, Kamphorst AO, Landthaler M, et al: A mammalian microRNA expression atlas based on small RNA library sequencing. Cell 129: 1401-1414, 2007.

11. Chang J, Nicolas E, Marks D, Sander C, Lerro A, Buendia MA, Xu C, Mason WS, Moloshok T, Bort R, et al: miR-122, a mammalian liver-specific microRNA, is processed from her mRNA and may downregulate the high affinity cationic amino acid transporter CAT-1. RNA Biol 1: 106-113, 2004.

12. Xu T, Zhu Y, Xiong Y, Ge YY, Yun JP and Zhuang SM: MicroRNA-195 suppresses tumorigenicity and regulates G1/S transition of human hepatocellular carcinoma cells. Hepatology 50: 113-121, 2009.

13. O'Reilly LA, Print C, Hausmann G, Moriishi K, Cory S, Huang DC and Strasser A: Tissue expression and subcellular localization of the pro-survival molecule Bcl-w. Cell Death Differ 8: 486-494, 2001.

14. Lee HW, Lee SS, Lee SJ and Um HD: Bcl-w is expressed in a majority of infiltrative gastric adenocarcinomas and suppresses the cancer cell death by blocking stress-activated protein kinase/c-Jun NH2-terminal kinase activation. Cancer Res 63: 1093-1100, 2003

15. Bae IH, Park MJ, Yoon SH, Kang SW, Lee SS, Choi KM and Um HD: Bcl-w promotes gastric cancer cell invasion by inducing matrix metalloproteinase-2 expression via phosphoinositide 3-kinase, Akt and Sp1, Cancer Res 66: 4991-4995, 2006.

16. Kitamura S, Kondo S, Shinomura Y, Kanayama S, Miyazaki Y, Kiyohara T, Hiraoka S and Matsuzawa Y: Met/HGF receptor modulates bcl-w expression and inhibits apoptosis in human colorectal cancers. Br J Cancer 83: 668-673, 2000.

17. Gibson L, Holmgreen SP, Huang DC, Bernard O, Copeland NG, Jenkins NA, Sutherland GR, Baker E, Adams JM and Cory S: bcl-w, a novel member of the bcl-2 family, promotes cell survival. Oncogene 13: 665-675, 1996.

18. Ma L, Liu J, Shen J, Liu L, Wu J, Li W, Luo J, Chen Q and Qian C: Expression of miR-122 mediated by adenoviral vector induces apoptosis and cell cycle arrest of cancer cells. Cancer Biol Ther 9: 554-561, 2010.

19. Wu X, Wu S, Tong L, Luan T, Lin L, Lu S, Zhao W, Ma Q, Liu $\mathrm{H}$ and Zhong Z: miR-122 affects the viability and apoptosis of hepatocellular carcinoma cells. Scand J Gastroenterol 44: 1332-1339, 2009.

20. Shen L, Li J, Xu L, Ma J, Li H, Xiao X, Zhao J and Fang L: miR-497 induces apoptosis of breast cancer cells by targeting Bcl-w. Exp Ther Med 3: 475-480, 2012.

21. Young DD, Connelly CM, Grohmann C and Deiters A: Small molecule modifiers of microRNA miR-122 function for the treatment of hepatitis $\mathrm{C}$ virus infection and hepatocellular carcinoma. J Am Chem Soc 132: 7976-7981, 2010.

22. Martinou JC, Desagher S and Antonsson B: Cytochrome $c$ release from mitochondria: All or nothing. Nat Cell Biol 2: E41-E43, 2000

23. Bai S, Nasser MW, Wang B, Hsu SH, Datta J, Kutay H, Yadav A, Nuovo G, Kumar P and Ghoshal K: MicroRNA-122 inhibits tumorigenic properties of hepatocellular carcinoma cells and sensitizes these cells to sorafenib. J Biol Chem 284: 32015-32027, 2009. 